\title{
Importancia de los abogados/as para el sostenimiento de la democracia ${ }^{1}$
}

\author{
Farith Simon \\ Universidad San Francisco de Quito
}

\section{Resumen}

En esta época marcada por un posmodernismo que pone en duda todo concepto o categoría, en un contexto de relativismo conceptual cada vez más extremo, este artículo explora la contribución de los abogados/as al fortalecimiento de la democracia, del Estado de Derecho, en el marco de una transformación del mundo jurídico latinoamericano, a partir de la superación de las dictaduras en el siglo pasado, que ha devenido en una serie de reformas constitucionales que se han concretado en algunas decisiones judiciales y en la producción de una nueva y amplia literatura jurídica escrita en clave de una supuesta innovación. ¿Qué papel tenemos los profesionales en este contexto? ¿Cuáles son nuestras contribuciones? ¿Existe una relación directa entre el ejercicio de la profesión y la defensa de los derechos o de la democracia? ¿Vivimos una nueva realidad jurídica?

\begin{abstract}
In this time, in which through postmodernism every category is questioned in a context of extreme conceptual relativism, this article explores the contribution that lawyers have had in several important topics. The strengthening of democracy as well as the Rule of Law that came after the dictatorships from last century, have transformed the legal systems in Latin America. This process has allowed several constitutional reforms, which have been materialized in judicial decisions, as well as a large production of innovative legal literature. What is the role of law-related professionals in this context? Which are our main contributions as lawyers? Is there a relationship between being a lawyer and defending rights or democracy? Are we living a new judicial reality?
\end{abstract}

Palabras clave:Profesión legal / Estado constitucional / Estado de Derecho / Constitucionalismo / Pluralismo jurídico / Diversidad cultural.

\section{Key Words}

Legal Profession / Constitucional State / Rule of Law / Constitutionalism / Legal Pluralism / Cultural Diversity.

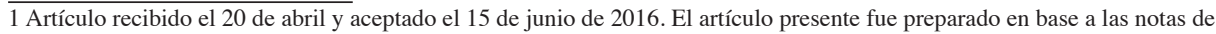
la participación del autor en la Conferencia de Internacional Bar Asocciation "Conmemorando la Carta Magna y el Estado de Derecho", Sao Paulo, 13 de noviembre del 2015. Nota del autor.
} 
Sumario 1. La profesión legal: una profesión instrumental 2) Defender la diversidad y el pluralismo, pero no todas las ideas o formas de vida merecen la mis consideración 3) No ceder a la tentación de que todo lo "nuevo" es un sinónimo de avance 4) El compromiso de los/as miembros de la profesión legal con la democracia, en sus aspectos sustanciales y no solo en su dimensión formal 4.1. Diferencias entre tradiciones jurídicas profesionales 4.2 Democracia formal y sustancial 4.3. Compromiso del ejercicio jurídico con la democracia formal y sustancial.

\section{La profesión legal: una profesión instrumental}

Alejandro Nieto 2 sostiene que los abogados/as cumplimos a la perfección las reglas de Darwin sobre la adaptación de las especies: somos capaces de asumir las nuevas condiciones del entorno y seguir trabajando incluso en las circunstancias más adversas y sobrevivir. Se registra en la historia reciente del mundo occidental un solo caso en que el entorno hizo imposible el desarrollo de la profesión legal en la dimensión de su libre ejercicio o representación de intereses particulares: el socialismo de la Unión Soviética. Allí los abogados/as fueron "engullidos/as" (por seguir con las analogías provenientes de la biología) por un inmenso aparato institucional que los transformó en funcionarios/as al servicio del régimen.

Esta idea de la "adaptación" se constituye a partir de un hecho evidente (aunque extensamente negado por la versión prusiana ${ }^{3}$ de la profesión jurídica, presente en Latinoamérica ${ }^{4}$ ): los abogados y abogadas representan intereses, los de sus clientes, que se esperaría coincidan siempre con la legalidad o nuestro sentimiento de lo justo. Sin embargo, muchos profesionales aceptan, o usando la terminología anterior, se adaptan, a proyectos políticos claramente autoritarios, que en el siglo XXI, en algunos países de América Latina, han asumido formas supuestamente "democráticas" al tener su origen en elecciones generales; pero que una vez en el poder, a través del uso del discurso de la "refundación" del Estado, de aquel de ser una alternativa al neoliberalismo u otro, más general, de superación de problemas reales (como la entrega del Estado a intereses particulares o la poca eficiencia del

\footnotetext{
2 Nieto, Alejandro, Crítica de la Razón Jurídica, Trotta, Madrid, 2007, p. 228.

3 Por poner un ejemplo: "Un edicto de Federico el Grande de 14 de abril de 1780 dice que los Abogados hacen interminables los pleitos porque cumple así á(sic) sus intereses y, oscureciendo los hechos, dificultan la recta administración de la justicia: fundado en estas razones, ordena que serán pagados de un fondo comun (sic) y que su mision (sic) se concretará á analizar los hechos y servir de asesores á los magistrados, de modo que en cuanto al hecho ayudan al Juez; por lo que al Derecho respecta son los defensores de la parte; a fuer(sic) de servidores de la verdad, no deben embrollar los procedimientos, ni alargarlos arbitrariamente; si otra cosa hicieren incurren en las pena de degradación, de prisión y de reclusión. Dióseles (sic) en este edicto el nombre de Consejeros asistentes, institucion (sic) que duró poco tiempo y fué (sic) reemplazada por los de los Comisarios de justicia, nueva organización que, aunque más liberal, no quitó á los Abogados su carácter de empleados del Gobierno, pero concedió á la parte la facultad de elegir su defensor y á éste el derecho de hacerse remunerar por su cliente". Sociedad de Legislación Comparada de París, Revista general de legislación y jurisprudencia, Año vigésimosegundo, Tomo XLV, Madrid, 1874 , pp. 348 y 349 .

4 En el Ecuador el artículo 323 del Código Orgánico de la Función Judicial reza: "LA ABOGACÍA COMO FUNCIÓN SOCIAL.-La abogacía es una función social al servicio de la justicia y el derecho. Es garantía fundamental que toda persona ser patrocinada por un abogado de su libre elección”. En la misma ley al referirse a los deberes del abogado en el patrocinio de una causa se dice (art. 330.1) "Actuar al servicio de la justicia y para este objeto colaborar con los jueces y tribunales".
} 
aparataje estatal) alimentan sistemas de reparto de favores o de carácter clientelar, ${ }^{5}$ que terminan promoviendo la corrupción. Justamente, las reformas constitucionales amplias de ciertos procesos políticos recientes de América Latina han servido de base para la configuración de proyectos antidemocráticos y tendencialmente autoritarios que vulneran varios supuestos fundamentales, a partir de una retórica simplista. La independencia de las funciones y los poderes del Estado se supera cuando se dice que el sistema de pesos y contrapesos es una "innovación burguesa"; se restringen las libertades más básicas usando el discurso de la libertad como igualdad de resultados y no como autonomía subjetiva; se diseñan instituciones que se ponen al servicio de un Estado al que, incluso, se le llegan a atribuir derechos básicos.

Servido el contexto, la profesión legal es esencialmente de carácter instrumental y por ello puede ser puesta al servicio de la obtención de los objetivos más sublimes o más abyectos, algunos de estos últimos "encubiertos" en nociones de éxito, eficacia profesional o en discursos aparentemente democráticos o de protección y garantía de derechos. No obstante, el que los abogados/as se comprometan con los valores de una sociedad democrática o su fortalecimiento es un deber ser, una expectativa compartida por muchas personas, dentro y fuera de la profesión.

Justamente, a partir de estas complejas y contradictorias ideas examinaré la relación entre profesión legal y fortalecimiento de la democracia usando tres ideas interrelacionadas en un contexto de cambio permanente: 1) la defensa la diversidad y el pluralismo, aunque puntualizando que no todas las ideas o formas de vida merecen la mis consideración; 2) el imperativo de no ceder a la tentación de que todo lo "nuevo" es un sinónimo de avance; y 3 ) la idea de que el compromiso con la democracia de los miembros de la profesión legal debe tomar sus aspectos sustanciales y no únicamente su dimensión formal.

\section{Defender la diversidad y el pluralismo, pero no todas las ideas o formas de vida merecen la mis consideración ${ }^{6}$}

El posmodernismo y su escepticismo ético han llevado a profundizar la idea de que toda forma de convivencia humana debe ser respetada. Se presenta, así, constantemente una pregunta: ¿cómo podríamos enjuiciar las prácticas de otros/as como adecuadas o inadecuadas sino usamos algún modelo considerado optimo o ideal? En efecto, pareciera que cualquier cuestionamiento de la alteridad implicaría una suerte de "poscolonialismo" valorativo que rompería con la propia idea de democracia y diversidad.

En buena medida, este difundido escepticismo ha hecho que el valor universal de los derechos humanos se ponga en duda, lo cual ha provocado el debilitamiento de la retórica y la práctica jurídica, abriendo las puertas a una actitud de relativismo en el que todo parece tener el mismo valor, tal como sostiene Ernesto Garzón Valdez:

\footnotetext{
5 Pérez Perdomo, Rogelio, "Venezuela: Derecho en una democracia renqueante", Culturas Jurídicas Latina de Europa y América en tiempos de Globalización, UNAM, México D.F., 2003, p. 709.

6 Tomo esta idea de Ernesto Garzón Valdés a quién citaré varias veces en este ensayo.
} 
Una mala defensa de la democracia es la que aduce en su favor la vigencia incontrolada del pluralismo valorativo y que ha dado lugar a malos entendidos y falsos ataques como los lanzados por los Critical Legal Studies en contra del rule of law y del Estado de derecho. ${ }^{7}$

Esta aseveración no trata de abogar por alguna forma de absolutismo ético. Sin embargo es indispensable reafirmar la importancia de los derechos humanos y su universalidad (su defensa, garantía y promoción) como una condición necesaria para calificar a una sociedad como democrática.

En este sentido, no podemos perder de vista, como advierte Alain Supoit, ${ }^{8}$ que es indiscutible que a los derechos humanos se les asigna un carácter dogmático y que su origen es claramente occidental, pero esto no resta su importancia y la necesidad de buscar su vigencia como referente central de la convivencia humana de modo más amplio.

Por ejemplo, en 1947, un grupo de la Asociación de Antropólogos Americanos, propuso que en la Declaración Universal de Derechos Humanos de las Naciones Unidas se incluyera una cláusula en que se dijese que la persona es libre "sólo cuando vive como su sociedad define la libertad". ${ }^{9}$ Esta petición fue negada porque dicha disposición convertiría a los derechos en inútiles. Efectivamente, ser demócrata y aceptar el pluralismo no significa dejar de lado la defensa de la universalidad de los derechos humanos. En realidad, la idea del aislacionismo moral (en otras palabras, que deba abandonarse cualquier consideración prescriptiva universal) no es compatible con una sociedad basada en los derechos humanos, pues del simple hecho que "existan diversas culturas no es posible inferir sin más que se deba respeto de las respectivas normas morales de cada cultura ni que esta diversidad sea valiosa". ${ }^{10}$ Por el contrario, y para rebatir propuestas en exceso relativistas, desde la génesis de los derechos humanos se encuentra la dicotomía entre:

[...] dos proposiciones centrales: el derecho a la autodefensa y la prohibición de dañar arbitraria o innecesariamente a sus semejantes [... ]. Si se toman en cuenta estos dos principios, que apuntan a necesidades universales de toda sociedad, no cuesta mucho inferir un buen catálogo de derechos humanos, también universales, formulables desde [una] posición de imparcialidad". ${ }^{11}$

3. No ceder a la tentación de que todo lo "nuevo" es un sinónimo de avance En los últimos años en América Latina se han producido una serie de transformaciones normativas e institucionales, muchas de las cuales han sido difundidas como formas de superación de los grandes males que muchos de nuestros países

\footnotetext{
7 Garzón Valdés, Ernesto, "Diez mandamientos para la vida universitaria”, Revista Isonomía, No. 9, octubre 1998, p. 55. 8 Supoit, Alain, Homo jurídicos, Siglo XXI Editores, Buenos Aires, 2007, p. 244.

9 Lukes, Steven, Relativismo moral, Paidós, Madrid, 2011, p. 64.

10 Garzón Valdés, Ernesto, "Cinco confusiones acerca de la relevancia moral de la diversidad cultural”, Claves de la Razón Práctica, No. 74, Julio-Agosto, 1997, p. 13.

11 Ibídem, p. 14
} 
han enfrentado, tales como el autoritarismo, la corrupción, la inestabilidad, la inseguridad, la exclusión. Muchas de esas innovaciones han recibido importantes adhesiones y amplio apoyo por su novedad, sin muchas veces detenerse a establecer el verdadero impacto de sus proyectos en el fortalecimiento de los derechos y la democracia.

A partir de la superación de las dictaduras en el siglo pasado se realizaron varias reformas constitucionales que se han concretado en algunas decisiones judiciales y en la producción de una nueva y amplia literatura jurídica escrita en clave de una supuesta innovación. Sin embargo no existe acuerdo en relación al alcance y características de esa reforma. Se pueden identificar tres tendencias al respecto. La primera que sostiene la aparición de un nuevo constitucionalismo latinoamericano; una segunda que niega ese nuevo constitucionalismo pero que acepta que existen varios cambios vinculados con los derechos; y la tercera, que también rechazando la existencia de un nuevo constitucionalismo defiende, no obstante, la existencia de un Ius Constitutionale Commune transformador.

La primera tendencia que afirma la existencia de un nuevo constitucionalismo latinoamericano, ${ }^{12}$ tiene como características principales, además de los aspectos

\footnotetext{
12 En algunos casos se habla de neoconstitucionalismo y sin embargo algunos autores consideran que es un fenómeno diferente al nuevo constitucionalismo latinoamericano. El neoconstitucionalismo pretende sin ruptura, alejarse del positivismo teórico y convertir al Estado de Derecho en el Estado Constitucional de Derecho. Se entiende que la constitución es una norma jurídica superior que condiciona a todo el ordenamiento y no puede ser modificada por el legislador ordinario; son los principios, y no las reglas, los que ordenan el contenido de todos los actos del poder público, produciendo así una ruptura con el positivismo, esto a partir del reconocimiento de un amplio catalogo de derechos. Sin embargo para Viciano Pastor y Martínez Dalmau la diferencia central es que el neoconstitucionalismo es resultado de un proceso de reflexión académica, en tanto que el nuevo constitucionalismo latinoamericano sería "un fenómeno surgido en el extrarradio de la academia, producto más de las reivindicaciones populares y de los movimientos sociales que de planteamientos teóricos coherentemente armados". Viciano Pastor, Roberto; Martínez Dalmau Rubén, "Fundamentos teóricos y prácticos del nuevo constitucionalismo latinoamericano", Gaceta Constitucional, No. 48, diciembre 2011, p. 7. Los autores han trabajado otros textos útiles en este sentido: "El nuevo constitucionalismo latinoamericano: fundamentos para una construcción doctrinal”, Revista General de Derecho Público comparado, No. 9, 2011; "El nuevo constitucionalismo en América Latina, Memorias del encuentro internacional”, El nuevo constitucionalismo: desafíos y retos para el siglo XXI, Corte Constitucional del Ecuador para el Período de Transición, Quito, 2010; "La Constitución democrática entre el neoconstitucionalismo y el nuevo constitucionalismo", Debates constitucionales en nuestra América: enfoques y tendencias, ILSA, Bogotá, 2014. También existe una propuesta de identificar a las constituciones de Ecuador y Bolivia como representantes de lo que han denominado "Constitucionalismo andino" o "Neoconstitucionalismo Andino transformador", a propósito de este tema se puede revisar el trabajo de Ramiro Avila "El Neoconstitucionalismo Andino", UASB, Quito, 2016; en este trabajo se proponen dos elementos para caracterizarla "neoconstitucionalismo andino transformador", que se nutre -según él- de las reinvindicaciones sociales y que se convierten en conquistas jurídicas, muchas como que afirma han aparecido en primer lugar en el mundo andino, particularmente en Bolivia y Ecuador, aunque asigna algún papel a la jurisprudencia peruana y colombiana. En todo caso define neoconstitucionalismo como "la teoría de los derechos fundamentales puesto en el centro de la teoría del derecho y el estado" (p. 38), que considera supera a una noción civilista en la que se da centralidad a "la ley, de la propiedad, del mercado, de la autonomía de la voluntad, del derecho subjetivo, del estado, del orden público, de los principios generales, de la civilización del progreso", sino que "debe construirse a partir de las personas y colectividades y sus derechos" (p.38). Al neoconstitucinalismo, dice el autor, hay que añadirle la palabra "transformador" porque afirma “...pretende alterar la realidad, que es la exclusión, marginalidad y discriminación, y la transformación de un sistema y una forma de vida 'colonizada' a una de emancipación de las grandes mayorías de la población, que no pueden ejercer sus derechos y que el estado les ofrece políticas paternalistas o simplemente represión penal" (p. 39), incluso llega a afirmar que este es un nuevo paradigma emergente con "potencial liberador sin precedentes en la historia del derecho".
} 
materiales que serían comunes al llamado neoconstitucionalismo, ${ }^{13}$ el hecho de que se establece un vínculo directo entre democracia y nuevo constitucionalismo, desde la legitimidad proveniente del amplio apoyo social que arroparon estas reformas ${ }^{14}$ y que, en cambio, no tuvieron las reformas constitucionales previas. Así, el sustento de las reformas constitucionales recae en el poder constituyente popular. ${ }^{15}$ En tal virtud, sus defensores/as lo describen como un "constitucionalismo comprometido" que busca "avanzar por el camino de la justicia social, la igualdad y el bienestar de los ciudadanos". ${ }^{16}$ Además, vale comentar que se caracteriza a este grupo de constituciones desde conceptos que valoran su carácter original, amplio, complejo y rígido. ${ }^{17}$

La segunda tendencia, por el contrario, niega la existencia de ese nuevo constitucionalismo latinoamericano y afirma que tiene "poco de nuevo". Aunque pueden encontrarse avances importantes en el reconocimiento de derechos (por ejemplo, su amplitud), se aduce que estos quedan limitados o restringidos por las normas que reproducen una institucionalidad proveniente del siglo XIX. Así, se reproduce una organización del poder (híper-presidencialista) que permite la concentración, sin alternativas institucionales que permitan un balance adecuado de esos poderes, pese a que se diseñaron nuevas instituciones o se afirmó que ampliar la participación popular era el medio adecuado para limitar esos poderes exacerbados. ${ }^{18}$ De

13 En lo material estarían caracterizadas por una democracia participativa como forma de control del poder y legitimidad del mismo; profusas cartas de derechos, individualización y colectivización de derechos, máxima efectividad de los derechos sociales, normas de interpretación, integración de grupos excluidos; nuevas formas de control concentrado de la constitucionalidad (o mixtos), como reafirmación del carácter normativo y superior de la Constitución; y, con una importante regulación en el campo económico con reconocimiento del papel del Estado en esta materia. Viciano, Roberto; Martínez Dalmau Rubén, “Aspectos generales”, p. 37.

14 Alejandro Medici afirma que "las nuevas constituciones [Bolivia, Venezuela y Ecuador] son producto de procesos de democratización radical, expresivas de una voluntad descolonizadora". La opción descolonial es "entendida como la perspectiva crítica que pretende llamar la atención sobre las continuidades históricas entre tiempos coloniales y poscoloniales; mostrar que las relaciones coloniales de poder van más allá del dominio económico-político y jurídico-administrativo y se afirman también en una dimensión epistémica, cultural, a partir de la cual se asigna superioridad cognoscitiva a los enunciados de regiones 'centrales' del sistema/mundo [...]. Colonialidad del poder que se identifica en la historia de desigualdades sociales y formas de opresión socioeconómica y cultural propias de una sociedad poscolonial, es decir, formalmente, desde lo jurídico, 'moderna', pero fácticamente opresora". Medici, Alejandro, "Nuevo constitucionalismo Latinoamericano y giro descolonial. Seis proposiciones para comprenderlo desde un pensamiento situado y crítico", Debates constitucionales en nuestra América: enfoques y tendencias, ILSA, Bogotá, 2014, p.

15 Un elemento común en los tres países que se consideran parte de ese nuevo constitucionalismo, Venezuela (1999), Ecuador (2008) y Bolivia (2009). No se consideran, en cambio, parte de este proceso, por su carencia de legitimidad democrática al guatemalteco de 1985, al brasileño de 1988, al colombiano de 1991 (que se le asigna muchas características del nuevo constitucionalismo), al peruano de 1993, y a las reformas argentinas de 1994. Sin embargo, en los tres países que se considera ejemplo del nuevo constitucionalismo se han promovido reformas constitucionales permanentes para favorecer el proyecto político coyuntural. En los tres casos se permite la reelección indefinida. En Venezuela se aprobó inicialmente en la Constitución, en el Ecuador esta reforma se encuentra en proceso de aprobación por medio de una enmienda constitucional a cargo de la Asamblea Nacional y en el caso de Bolivia esta posibilidad se abre por una decisión del Tribunal Constitucional.

16 Viciano Pastor Roberto; Martínez Dalmau Rubén "Fundamentos teóricos y prácticos”, p. 313.

17“[L]a ya relevante extensión del articulado (amplitud), la capacidad de conjugar elementos técnicamente complejos con un lenguaje asequible (complejidad), y el hecho de que se apuesta por la activación del poder constituyente del pueblo ante cualquier cambio constitucional(rigidez)". Ibídem. p. 322.

18 Las principales críticas al supuesto nuevo constitucionalismo, por las deficiencias al estructurar el poder, se encuentran en 
hecho, de acuerdo a los escépticos/as, la creación de esas nuevas estructuras institucionales contribuyeron al debilitamiento del poder legislativo (debido al control político), de las instancias de revisión administrativa financiera (por el control de cuentas) y del judicial (a través de la injerencia en la decisiones de los jueces, o por medio de cortes constitucionales con atribuciones para revisar decisiones de esas altas cortes). ${ }^{19}$

La tercera tendencia afirma que en América Latina existe un Ius Constitutionale Commune transformador ${ }^{20}$ y no un nuevo constitucionalismo, que se desarrollaría a partir del rechazo de las ideologías constitucionales tradicionales presentes históricamente en la región: conservadurismo, liberalismo y radicalismo. ${ }^{21}$ El Ius Constitutionale Commune $e^{22}$ es una búsqueda regional de la inclusión social que busca poner fin a la exclusión económica, social, cultural en que viven grupos significativos de la población. Dos son los elementos que le dan unidad: 1) la incorporación en los ordenamientos jurídicos de las normas de derechos humanos provenientes del derecho internacional; en particular de la Convención Americana de Derechos Humanos, así como la interpretación que de estas hace la Corte Interamericana; y, 2) la elaboración de un derecho comparado común que se crea a partir de ciertas pautas compartidas. De esta manera, lo que se busca es "garantizar a escala regional la realización de las promesas centrales de las constituciones estatales", reconociendo la débil normatividad de las disposiciones que reconocen derechos sociales. ${ }^{23}$

Este postulado regional se consigue a partir de la convivencia de tres principios fundamentales: derechos humanos, democracia y Estado de derecho. En el caso de los derechos se dice que se caracterizan por la "indivisibilidad e interdependencia de los derechos humanos, en particular de los derechos civiles respecto de los sociales... así el derecho y los tribunales deberían estar al servicio de los grupos sociales marginalizados", ${ }^{24}$ con énfasis en la dimensión colectiva de los derechos fundamentales.

\footnotetext{
los trabajos de Gargarella, Roberto. Cfr. "El constitucionalismo latinoamericano y la 'sala de máquinas' de la constitución (1980-2010)", Gaceta Constitucional No. 48, diciembre 2011. En cuanto material divulgativo del mismo autor vale la pena revisar la columna "Nuevo constitucionalismo latinoamericano" publicado en el diario El País el 20 de agosto del 2014, http:// elpais.com/elpais/2014/07/31/opinion/1406816088_091940.html

$19 \mathrm{El}$ ejemplo extremo de este proceso de debilitamiento se puede encontrar en el llamado "Poder Ciudadano" y su "Consejo Moral Republicano en Venezuela; la "Función de Transparencia y Control Social" y su "Consejo de Participación Ciudadana y Control Social" en el Ecuador; y, "Participación y Control Social

20Esto es parte de un proceso de intercambio académico entre el Instituto Max Planck de Derecho Público Comparado y Derecho Internacional y expertos latinoamericanos, en el libro "Ius Constitutionale Commune" en América Latina. Rasgos, potencialidades y desafíos, coordinado por von Bogdandy, Armin (et. al).

21 En esto siguen a Gargarella en su propuesta contendida en Latin American Constitutionalism 1810-2010. The Engine Room of the Constitution, Oxford, 2013, pp. 197 y sgts.

22 Voy a seguir la caracterización que hace Armin Von Bogdandy en su artículo "Ius Constitutionale Commune en América Latina: una mirada a un constitucionalismo transformador", Revista Derecho del Estado (Nueva Serie), No. 34, enero-junio 2015, pp. 1-50.

23 Ibídem, p. 15.

24 Ibídem, p. 19.
} 
Por ello, los defensores/as de esta línea, en cuanto al requisito de la democracia, cuestionan el (hiper)presidencialismo mostrado por ciertos Estados ${ }^{25}$ ya que "obstaculiza otros aspectos importantes del gobierno democrático: la representación parlamentaria, la deliberación, así como la separación de poderes y el reparto de las competencias"; ${ }^{26}$ quedándose principalmente en "la representatividad y la deliberación, con el fin de fortalecer la institucionalidad". ${ }^{27}$ Así, si bien quienes argumentan a favor de esta línea valoran la contribución de la justicia en el desarrollo de derechos relevantes, sin embargo advierten de peligrosos usos de este sistema de justicia en ciertos contextos, como por ejemplo en Venezuela y Ecuador.

En adición, se puede ver que estos estudiosos/as destacan una "internacionalización del derecho constitucional" y una "constitucionalización del derecho internacional" pues se da una apertura al derecho internacional público, en particular debido a la creación de un corpus iuris de derechos humanos ${ }^{28}$ y la introducción del denominado del control constitucional. Finalmente mencionan, como central en la propuesta, un "pluralismo dialógico" que designa una "modalidad de interacción social para la resolución de conflictos"; lo que implica la "inclusión de la población indígena y afrodescendiente, es decir, darles espacio en las instituciones estatales y reconocer que son grupos con valores e intereses específicos". ${ }^{29}$ Aunque en realidad el fenómeno ha sido inverso pues, por ejemplo, ha sido la Corte Interamericana de Derechos Humanos la que ha ido forzando la incorporación a nivel local de la mayoría de esos conceptos; es decir no existe tal "diálogo" como se querido ver con demasiado optimismo.

\section{El compromiso de los/as miembros de la profesión legal con la democracia, en sus aspectos sustanciales y no solo en su dimensión formal}

\subsection{Diferencias entre tradiciones jurídicas profesionales}

A los abogados y abogadas, en la versión prusiana de la profesión, se nos asigna el papel de auxiliares de la justicia o del Derecho. ${ }^{30}$ En la visión anglosajona, que tiene en la actualidad una amplia repercusión, el abogado/a representa intereses y recae sobre él o ella la expectativa de que los realice dentro de los límites normativos (los

\footnotetext{
$25 \mathrm{Al}$ respecto se puede leer de Roberto Gargarella, "La 'sala de máquinas' de las constituciones latinoamericanas. Entre los viejo y lo nuevo", Revista Nueva Sociedad, No. 258, Julio-Agosto 2015, pp. 96-106.

26 Von Bogdandy, Armin, Ius Constituionale Commune, p. 20.

27 Ibídem p. 21.

28 Ibidem, p. 31.

29 Ibídem, p. 33.

30 Es abundante la literatura que asigna ese papel a los abogados. En muchos países se encuentra normado: el artículo 323 del Código Orgánico de la Función Judicial del Ecuador (vigente desde el 2009 ) establece "La abogacía es una función social al servicio de la justicia y del derecho...”. Desde la perspectiva de los mismos abogados esto es mirado así, por ejemplo el primer artículo del Código de Ética profesional “Avellan Ferres”, aprobado por la Federación Nacional de Abogados del Ecuador en 1969 (y vigente hasta el momento) en su artículo 1 establece "El Abogado es un servidor de la justicia y un colaborador de su administración...". El "Decálogo del Abogado" de Eduardo Couture, ampliamente difundido dice "Trabaja. La abogacía es una dura fatiga pues está al servicio de la Justicia”. El art. 2 del Código de Ética e disciplina de OAB “O advogado, indispensável à administração da Justiça, é defensor do estado democrático de direito, da cidadania, da moralidade pública, da Justiça e da paz social, subordinando a atividade do seu Ministério Privado à elevada função pública que exerce".
} 
que se espera correspondan con los derechos). Así, en nuestro contexto profesional se asigna un deber ser que en muchas ocasiones, más de las que nos gustaría, no se corresponde con la realidad de la práctica profesional.

La existencia de una sociedad democrática que ipso facto se asocia con un Estado de derecho, no implica solamente la primacía de las normas por sobre las personas, sino que cada grupo social puede satisfacer sus derechos más allá de sectarismos. Para los empresarios, o quienes hacen negocios, la democracia bajo un Estado de derecho se concretaría, por ejemplo, a través de "reglas estables, predecibilidad de las conductas de los funcionarios, existencia de jueces honestos y eficiencia en la ejecución de los contratos". ${ }^{31}$ Sin embargo, dicho entorno legal podría existir perfectamente en un contexto autoritario, ${ }^{32}$ pues el Estado de derecho es el sometimiento de todas las personas a las normas, pero no implica el reconocimiento de derechos, la real división de poderes, la independencia de la justicia o la realización de elecciones periódicas, transparentes, etc. Cosa que sí sucede con el concepto rule of law. Cuestión que debe considerarse para el ejercicio profesional de la abogacía.

\subsection{Democracia formal y sustancial}

No se puede entender la democracia únicamente en su dimensión formal o procedimental. Para asegurar un gobierno de las mayorías existen también los límites a ese poder. Así, el "juego democrático" va mucho más allá de procedimientos de elección, e implica una serie de limitaciones a los ámbitos de decisión de las mayorías y el establecimiento claro de los objetivos que todo Estado democrático debe alcanzar. En suma: el votar, la realización de elecciones periódicas y las reglas a favor de la mayoría son condiciones necesarias pero no suficientes para juzgar a una sociedad como democrática.

Además de las condiciones institucionales (tales como la separación e independencia de los poderes) una democracia debe ser evaluada en relación a los derechos. No me refiero a la solamente a la dimensión política/procesal sino a aquella valorativa (que desde luego se espera se encuentre normativamente expresada) y que pone en correlación el respeto a las reglas constitucionales, los derechos de las minorías, los derechos de los individuos, al reconocimiento de la pluralidad, etc. La democracia, en consecuencia, como forma de gobierno puede ser enjuiciada en dos dimensiones, una formal y una material.

En su dimensión formal la democracia implica una organización institucional y condiciones que aseguren que las decisiones se tomen efectivamente por parte de las

\footnotetext{
31 Pérez Perdomo, Rogelio; Friedman, Lawrence, Introducción, publicado en Culturas Jurídicas latinas de Europa y América en tiempos de Globalización, UNAM, México D.F., 2003, p. 21.

32 Joseph Raz considera que el Estado de derecho "al favorecer la predictibilidad, la transparencia, la generalidad y la imparcialidad, y otorgar integridad a la aplicación de la ley, el Estado de derecho se convierte en la antítesis del poder arbitrario". Raz, Josep, The Authority of Law: Essays on Law and Morality, Clarendon Press, Nueva York, 1979, p. 19. Aquí suele fortalecerse el papel de los abogados lobistas, con contactos en el poder y con capacidad de influir en las decisiones políticas. En general en contextos autoritarios, o de corrupción, la personas tienden a elegir a sus abogados por su capacidad de gestión ante las autoridades, más que su capacidad académica, profesional, en el manejo de casos. Esta y todas las traducciones son del autor.
} 
mayorías. Así, la legitimidad de las decisiones se sustenta en la forma en que estas se producen, lo cual implica la subordinación del Derecho a las decisiones políti$\operatorname{cas}^{33}$ y propone una concepción mínima que pone su acento en el modo en que se toman "decisiones colectivas, las decisiones que interesan a toda la colectividad, con el máximo del consenso y el mínimo de violencia". ${ }^{34}$ Mientras se cumplan ciertas reglas, a decir: la selección periódica de los dirigentes, el uso de mecanismos destinados para evitar que estos se perpetúen en el poder; y, la decisión por parte de las mayorías, ${ }^{35}$ la formalidad de la democracia está bastante garantizado.

Lo enumerado implica entender cómo y quién decide sin embargo no establece el qué puede se puede o no decidir. Por ello se considera que existe una dimensión sustancial de la democracia que se refiere al qué se decide, que es el punto radical que busco subrayar en este artículo.Alguien formado en el contexto anglosajón relaciona inmediatamente el Rule of Law con la separación de poderes y el respeto a los derechos y libertades. Sin embargo en el contexto del derecho continental, Estado de derecho y democracia formal no tienen una relación unívoca con los derechos. Es por ello que se considera que el nuevo paradigma que subsana este fallo es el del Estado constitucional de derecho: el garantismo, concebido como un "modelo de derecho basado en la rígida subordinación a la ley de todos poderes y los vínculos impuestos de estos garantías los derechos, con preferencia de los derechos fundamentales". ${ }^{36}$ Esto tiene como consecuencia que todos los poderes del Estado tienen como límite de sus decisiones a los derechos. Además de estar obligados a asegurarlos. Aparece una pregunta inevitable: ¿cuáles derechos? Y la respuesta es: todos, a partir de la noción de integralidad e interdependencia.

Partiendo desde esta perspectiva, contribuir a la democracia regional implicaría un compromiso con cómo y quién decide; una organización institucional que asegure un balance de poderes. Pero también con lo que se decide. Así, todos los poderes estarían obligados a respetar (una perspectiva negativa) y garantizar (una perspectiva positiva) todos los derechos. Cabe recalcar que la democracia formal es un presupuesto indispensable de la democracia sustancial, pero en ningún caso suficiente. En sociedades donde la democracia es una realización incompleta todas las personas estamos expuestas al autoritarismo o a la anarquía.

\footnotetext{
33 Ferrajoli, Luigi, La democracia a través de los derechos, Trotta, Madrid, 2014, p.

34 Bobbio, Norberto, Teoría General de la Política, Trotta, Madrid, 2003, p. 459.

35 El mismo Bobbio enumera lo que considera los "procedimientos universales" de la democracia: 1) todos los ciudadanos que hayan alcanzado la mayoría de edad, sin distinción de raza, religión, condición económica y sexo, deben disfrutar de los derechos políticos, es decir, cada uno debe disfrutar del derecho de expresar la propia opinión y de elegir a quien la exprese por él; 2) el voto de todos los ciudadanos debe tener el mismo peso; 3) todos los que disfrutan de los derechos políticos deben ser libres para poder votar según la propia opinión, formada lo más libremente posible, es una competición libre entre grupos políticos organizados, en concurrencia entre ellos; 4) deben ser libres también en ese sentido de que deben ser puestos en la condición de elegir entre soluciones diversas, es decir, entre partidos que tengan programas diversos; 5) tanto para las elecciones como para las decisiones colectivas, debe valer la regla de la mayoría numérica, en el sentido de que se considere electa o se considere válida la decisión que obtenga el mayor número de votos; ninguna decisión tomada por mayoría debe limitar los derechos de la minoría, particularmente el derecho de convertirse a su vez en mayoría en igualdad de condiciones". Ibídem, p. 460.

36 Luigi Ferrajoli, La democracia a través, p. 29.
} 


\subsection{Compromiso del ejercicio jurídico con la democracia formal y sustancial}

Al inicio de este artículo hice una referencia al jurista español Alejandro Nieto y su afirmación de que los miembros de la profesión legal tenemos la capacidad de sobrevivir adaptándonos a las nuevas circunstancias. Yo añado que dicha adaptación se da a menudo aceptando condiciones institucionales y políticas abiertamente contrarias a valores mínimos de la sociedad actual que permitirían un marco de seguridad democrática para el cumplimiento de los proyectos de vida más diversos. De hecho, existen muchas evidencias de la facilidad con que la mayoría de los miembros de la profesión legal se adaptan el ejercicio de la profesión en condiciones abiertamente antidemocráticas; baste mirar los ejemplos en la dictaduras chilenas, argentinas, brasileñas, uruguaya, paraguaya, ecuatoriana, peruana, etc., de la década de los setentas y ochentas del siglo pasado. ${ }^{37}$ La verdad es que parece ser que en un Estado de derecho democrático "la frecuencia de las disputas interpersonales se reduce, con lo que la litigiosidad general declina", ${ }^{38}$ haciendo que abogados/as tengan menos trabajo, al menos en la vertiente del litigio. Así la evidencia muestra que durante las dictaduras, en general, la profesión jurídica se debilita. ${ }^{39}$

Por ello, en contextos autoritarios y poco democráticos, la profesión legal a menudo se ejerce a partir de la capacidad de influencia y de relación cercana con el poder. La elección de un abogado/a (o una firma de abogados) se suele hacer a partir de esos criterios ${ }^{40}$ y no los de capacidad y conocimiento. Así, se benefician solamente unos pocos profesionales que tienen acceso a los niveles de influencia, que además se encuentran sujetos siempre a la posibilidad de que alguien con mayores influencias y poder lo desplace u obtenga beneficios mayores para los intereses que se representan. Muchos profesionales del derecho se convierten en "gestores de corrupción" o lobistas frente al poder. Así, las nuevas condiciones no tienen relación con la capacidad, la preparación o la justicia del caso, sino simplemente con las redes y contactos que se puedan lograr.

En un contexto como el descrito es de esperar que la mayoría busque maximizar la ventaja inmediata, asumiendo que los demás actuarán de la misma forma, ${ }^{41}$ llegando a una situación que Carlos Nino calificó como "anomia boba":

\footnotetext{
37 Como ejemplo se puede consultar el trabajo de Fuenzalida Faivovich, Edmundo, "Derecho y cultura jurídica en Chile (1974-1999)", Culturas jurídicas latinas de Europa y América en tiempos de globalización, Héctor Fix-Fierro et. Al. (eds), México, Universidad Nacional Autónoma de México, 2003, p. 205. En este mismo trabajo se da cuenta de la importancia que tuvieron muchos abogados/as en la defensa de los derechos humanos por medio de la asesoría en la Vicaría de la Solidaridad o por medio de la conformación del llamado "Grupo de los 24", p. 227. Además muchos de los abogados/as "reformistas" fueron exiliados o asesinados.

38 Bergoglio, María Inés, "Argentina: efectos de la institucionalización”, Culturas jurídicas latinas de Europa y América en tiempos de globalización, Héctor Fix-Fierro et. Al. (eds), México, Universidad Nacional Autónoma de México, 2003, p. 104. 39 Desalay, Ives; Garth, Bryant, "Patrones de inversión jurídica extranjera: los casos de Brasil, Chile, México y Argentina", Culturas jurídicas latinas de Europa y América en tiempos de globalización, Héctor Fix-Fierro et. Al. (eds), México, Universidad Nacional Autónoma de México, 2003, p. 733.

40 Nieto los llama "corredores de influencia y gestores de corrupción". Nieto, Alejandro, Crítica de la Razón Jurídica, p. 238. 41 Cfr. Putnam, Robert, Making Democracy Work. Civic Tradittions in Moderm Italy, Princeton, Princeton University Press, 1993.
} 
[U]na acción colectiva es anómica, en el sentido de ilegalidad "boba" que aquí nos interesa, si ella es menos eficiente que cualquier otra que se podría dar en la misma situación colectiva y en la que se observara una cierta norma. [...] Hay anomia boba sólo cuando la acción colectiva en cuestión se caracteriza por la inobservancia de normas y hay al menos una cierta norma que conduciría a una acción colectiva más eficiente en la misma situación..$^{42}$

En un contexto así todas las personas se convierten en vulnerables y alguien logrará más poder, más recursos o mayor capacidad de influencia, etc. Además de abrir las puertas a la anarquía o al autoritarismo, muchos abogados/as podrán sacar provecho de esto y lograrán sobrevivir como lo han hecho en el pasado. En el fondo de esta reflexión aparece que no es una condición suficiente para ejercer la abogacía ser honesto, comprometerse con los valores sustanciales de la democracia o con los derechos humanos y es allí donde debe plantearse una crítica.

Los abogados/as tenemos una influencia relevante en la formación de lo público, además del impacto que tenemos con nuestra actuación en la asesoría caso a caso. Muchas veces nuestro rol es determinante en la formación de las políticas públicas. ${ }^{43}$ Tan es así que en numerosos casos somos quienes las diseñamos o -en la mayoría de ocasiones- asesoramos a quien las define. ${ }^{44}$ Asimismo, bajo nuestra responsabilidad informamos lo que consideramos posible o prohibido y ayudamos a interpretar el alcance de la permisiones y prohibiciones, su compatibilidad o incompatibilidad con los "valores" más importantes del sistema jurídico, que en último caso son los más relevantes de la vida social y política de un Estado.

¿En un contexto de defensa de sociedades plurales, ¿es posible defender algunos de esos "valores" como determinantes al optar por ellos y comprometernos con su vigencia? La respuesta es, para mí, un rotundo sí.

Los miembros/as de la profesión jurídica nos beneficiamos de la democracia cuando en esta se encuentran presentes sus aspectos formales y sustanciales, pero también nosotros tenemos un rol fundamental en el fortalecimiento de la democracia porque existe una relación simbiótica entre la democracia y un mejor trabajo jurídico que rompe con la anomia boba.

\footnotetext{
42 Nino, Carlos S., Un País al margen de la ley, Arial, Buenos Aires, 2005, p. 39

43 A propósito del nexo de la profesión legal con las políticas públicas es muy valioso el artículo publicado de Lasswell, Harold D.; McDougal, Myres S. "Legal Education and Public Policy: Professional Training in the Public Interest", The Yale Law Journal, volumen 52, marzo de 1943, pp. 202-295. Existe un versión resumida y traducida al español por Martín F. Böhmer "Enseñanza del derecho y políticas públicas: entrenamiento profesional para el interés público", publicado en "La enseñanza del derecho y el ejercicio de la abogacía", Martín F. Böhmer (compilador), Gedisa-Yale Law School y Universidad de Palermo, Barcelona, 1999, pp. 73-97.

44 "Al medir la influencia de los abogados se debe recordar además que ésta no se debe buscar en las ocasiones más espectaculares de su práctica profesional, tales como la redacción de una Constitución o de leyes generales, sino más bien en el efecto acumulado de muchas miles de descripciones de hechos o en las opiniones que los abogados brindan día a día en forma rutinaria", Ibídem, p. 76 .
} 
El compromiso de los abogados/as con los valores democráticos, con el Estado de derecho y con los derechos humanos es fundamental. En consecuencia, no toda forma de ejercer la profesión es aceptable sobre todo porque existe una relación simbiótica permanente y de mutuo interés: los abogados/as somos buenos para la democracia y la democracia es buena para el ejercicio de la profesión jurídica. 


\section{Bibliografía}

Ávila, Ramiro, El Neoconstitucionalismo Andino, UASB, Quito, 2016.

Bergoglio, María Inés, "Argentina: efectos de la institucionalización”, Culturas jurídicas latinas de Europa y América en tiempos de globalización, Héctor Fix-Fierro et. Al. (eds), Universidad Nacional Autónoma de México, México, 2003.

Bobbio, Norberto, Teoría General de la Política, Trotta, Madrid, 2003, pp. 27-117.

Desalay, Ives; Garth, Bryant, "Patrones de inversión jurídica extranjera: los casos de Brasil, Chile, México y Argentina", Culturas jurídicas latinas de Europa y América en tiempos de globalización, Héctor Fix-Fierro et. Al. (eds), Universidad Nacional Autónoma de México, México, 2003, pp. 723-749.

Ferrajoli, Luigi, La democracia a través de los derechos, Trotta, Madrid, 2014.

Fuenzalida Faivovich, Edmundo, "Derecho y cultura jurídica en Chile (1974-1999)", Culturas jurídicas latinas de Europa y América en tiempos de globalización, Héctor Fix-Fierro et. Al. (eds), México, Universidad Nacional Autónoma de México, 2003, pp. 195-231.

Gargarella, Roberto, “La 'sala de máquinas' de las constituciones latinoamericanas. Entre los viejo y lo nuevo", Revista Nueva Sociedad, No. 258, Julio-Agosto 2015, pp. 96-106.

"Nuevo constitucionalismo latinoamericano", El País digital, 20 de agosto del 2014, http://elpais.com/elpais/2014/07/31/opinion/1406816088_091940. html (consultado 02/02/2016).

Latin American Constitutionalism 1810-2010. The Engine Room of the Constitution, Oxford University Press, Oxford, 2013.

"El constitucionalismo latinoamericano y la 'sala de máquinas' de la constitución (1980-2010)", Gaceta Constitucional No. 48, diciembre 2011, pp. 289-305.

Garzón Valdés, Ernesto, "Diez mandamientos para la vida universitaria”, Revista Isonomía, No. 9, octubre 1998, p. 55.

Garzón Valdés, Ernesto, "Cinco confusiones acerca de la relevancia moral de la diversidad cultural", Claves de la Razón Práctica, No. 74, Julio-Agosto, 1997, pp. 10-23.

Lasswell, Harold D.; McDougal, Myres S., "Legal Education and Public Policy: Professional Training in the Public Interest", The Yale Law Journal, volumen 52, marzo de 1943, pp. 202-295.

Lasswell, Harold D.; McDougal, Myres S., "Enseñanza del derecho y políticas públi- 
cas: entrenamiento profesional para el interés público", La enseñanza del derecho y el ejercicio de la abogacía, Martín F. Böhmer (comp.), GedisaYale Law School y Universidad de Palermo, Barcelona, 1999, pp. 73-97.

Lukes, Steven, Relativismo moral, Paidós, Madrid.

Medici, Alejandro, "Nuevo constitucionalismo Latinoamericano y giro descolonial. Seis proposiciones para comprenderlo desde un pensamiento situado y crítico", Debates constitucionales en nuestra América: enfoques y tendencias, ILSA, Bogotá, 2014

Nieto, Alejandro, Crítica de la Razón Jurídica, Trotta, Madrid, 2007.

Nino, Carlos S., Un País al margen de la ley, Arial, Buenos Aires, 2005.

Pérez Perdomo, Rogelio, "Venezuela: Derecho en una democracia renqueante", Culturas Jurídicas Latina de Europa y América en tiempos de Globalización, UNAM, México D.F., 2003, pp. 723-749.

Pérez Perdomo, Rogelio; Friedman, Lawrence, "Introducción", Culturas Jurídicas latinas de Europa y América en tiempos de Globalización, UNAM, México D.F., 2003, pp. 1-26.

Putnam, Robert, Making Democracy Work. Civic Tradittions in Moderm Italy, Princeton, Princeton University Press, 1993.

Raz, Josep, The Authority of Law: Essays on Law and Morality, Clarendon Press, Nueva York, 1979

Sociedad de Legislación Comparada de París, publicado en Revista general de legislación y jurisprudencia, Año vigésimosegundo, Tomo XLV, Madrid, 1874, pp. 337-357.

Supoit, Alain, Homo jurídicos, Siglo XXI Editores, Buenos Aires, 2007.

Viciano Pastor Roberto; Martínez Dalmau Rubén, "La Constitución democrática entre el neoconstitucionalismo y el nuevo constitucionalismo", Debates constitucionales en nuestra América: enfoques y tendencias, ILSA, Bogotá, 2014.

"Fundamentos teóricos y prácticos del nuevo constitucionalismo latinoamericano", Gaceta Constitucional, No. 48, diciembre 2011 a, pp. 307-328.

"El nuevo constitucionalismo latinoamericano: fundamentos para una construcción doctrinal", Revista General de Derecho Público comparado, No. 9 , 2011 b, pp. 307-328.

"El nuevo constitucionalismo en América Latina, Memorias del encuentro internacional", El nuevo constitucionalismo: desafíos y retos para el siglo XXI, Corte Constitucional del Ecuador para el Período de Transición, Quito, 
2010, pp. 13-43.

Von Bogdandy, Armin, "Ius Constitutionale Commune" en América Latina. Rasgos, potencialidades y desafíos, Instituto de Investigaciones Jurídicas de la UNAM / Instituto Max Planck de Derecho Público Comparado y Derecho internacional, México D.F., 2014, pp. 3-25.

Von Bogdandy en su artículo "Ius Constitutionale Commune en América Latina: una mirada a un constitucionalismo transformador", Revista Derecho del Estado (Nueva Serie), No. 34, enero-junio 2015, pp. 1-50.

Leyes y códigos de ética

Von Bogdandy, Armin, "Ius Constitutionale Commune" en América Latina. Rasgos, potencialidades y desafíos, Instituto de Investigaciones Jurídicas de la UNAM / Instituto Max Planck de Derecho Público Comparado y Derecho internacional, México D.F., 2014, pp. 3-25.

Código Orgánico de la Función Judicial, Ecuador, 2009.

Código de Ética profesional "Avellan Ferres", http://www.uianet.org/sites/default/files/Ecuador_Codigo-Etica_1969_ES.pdf, 1969 (acceso: 02/02/2016)

Código de Ética e disciplina de OAB, http://www.oab.org.br/visualizador/19/codigode-etica-e-disciplina (acceso: 02/02/2016)

Couture, Eduardo, El Decálogo del Abogado, http://decalogodelabogado.org/ (acceso 02/02/2016) 